\title{
A máscara alegre: contribuições da cena gay para o teatro brasileiro *
}

\author{
Newton Moreno
}

I

ão raro o público de teatro refere-se às peças gays que entram em cartaz como mais uma peça gay que entra em cartaz. Peças de homossexuais, para homossexuais, com aquelas coisas que só homossexuais gostam. Muitas são as argumentações em defesa de uma ou outra encenação na tentativa de convencer amigos a assisti-las. No entanto, para a grande maioria, as peças que abordam o homoerotismo não constituem bom teatro e sim, manifestos de uma minoria em busca de uma conquista de espaço. São consideradas como prolongamentos de manifestações políticas, arena de lutas pelos direitos humanos, mas raramente são entendidas como espaço de uma criação teatral séria, de uma pesquisa de linguagem cênica ou de uma renovação vital e luminosa para a cena teatral brasileira. Isto quando não são diretamente associadas ao desfile de corpos bem talhados em academias e ponto.

Esta pesquisa surge de um inconformismo e de uma curiosidade; inconformismo quanto à desvalorização dessa produção e curiosidade de rastrear na história do palco brasileiro como foi organizada a discussão sobre o homoerotismo, quantos foram e efetivamente o que propunham; o artista e o ativista pediam o registro da crescente produção, um panorama histórico e uma análise crítica da importância para cena teatral destes espetáculos.

Indago-me se não seria mais prudente tentar entender a pesquisa de modo mais amplo: primeiramente, cobrindo as Artes Cênicas, porque estudo a contribuição estética, o mapeamento histórico, enfim a percepção da área teatral para esta produção; mas, ao organizar este material e dar-lhe perspectiva histórica, não estaremos sempre lidando com uma questão política de conquista de espaço para a causa gay?

Dois livros inspiraram a formatação deste trabalho: Not in Front of the Audience, de Nicholas de Jongh (1992), e Devassos no paraiso de João Silvério Trevisan (1986). O primeiro captura a trajetória da figura gay nos teatros de Londres e Nova York, centrando a discussão na imagem inferiorizada e estereotipada que lhe era imposta no palco. Seu estudo, entretanto, acaba revelando uma vasta rede de textos produzidos sobre a temática gay. De um obscuro texto escrito pela famosa atriz americana Mae West,

Newton Moreno é dramaturgo e pesquisador.

* Este texto foi apresentado no III Congresso de Cultura e Homoerotismo, na Universidade Federal Fluminense (UFF), em junho de 2001. Tem por objetivo resumir aspectos relevantes da pesquisa de Mestrado A máscara alegre: contribuiçôes da cena gay para o teatro brasileiro, que realizo no Departamento de Arte Cênicas da Universidade de São Paulo, sob orientação da Profa. Dra. Sílvia Fernandes Telesi. 
Drag, até uma peça polêmica, montada em várias partes do mundo, sobre a consciência da Aids na comunidade gay, The Normal Heart, de Larry Kramer. Parece óbvio o interesse despertado, ao final da leitura desse livro, em repetir o mesmo ritual de investigação pelos palcos brasileiros.

João Silvério construiu um livro que atravessa a vivência homossexual neste país em múltiplas áreas. Ensaio antropológico, sociológico, artístico, nada escapa à arqueologia voraz do autor. Um capítulo enfrenta a discussão dos palcos da nação brasileira, A cena travestida, levantando uma série de restriçôes quanto ao enfoque do gay em cena. Saltam aos olhos, contudo, suas observações sobre dois grupos teatrais, que pretendemos analisar com maior apuro, o Dzi Croquetes e o Vivencial Diversiones.

No livro Gender in Performance, outra referência para montagem deste projeto, Laurence Senelick observa que "O Teatro tem sido um lugar seguro para o comportamento não-convencional" e abre espaço para uma série de artigos que exploram antropologicamente a definição de papéis em cima do palco em diversas culturas. Em um dos artigos, Marjorie Garber explora a interseção entre o travestimento e as origens da arte teatral. Para que ocorresse o fenômeno teatral fez-se necessário o travestimento, causando dupla confusão subversiva entre a definição de papéis masculino/feminino e da realidade dentro e fora do palco.

No livro Presence and Desire, Jill Dolan (1993) discute, entre outros assuntos, a defesa por uma arte homossexual criadora de referências que promovam a identificação da comunidade gay, acuada por modelos heterossexuais. $\mathrm{O}$ imaginário gay carece de fontes e referências e o homossexual só se vê retratado em peças através do ponto de vista do artista heterossexual. É este quem dá essa visibilidade ao homossexual à sua maneira, é este quem 'dirige' o olhar. Em um dos artigos do livro, $A$ culture that isn't just sex, John Clum afirma, oportunamente, que parte desta visão do homo dentro da ótica heterossexual se dá sempre pela discussão da prática sexual. Como se fosse esta a única questão latente e vital a ser discutida. No livro, uma série de artigos reclamam uma outra construção do imaginário gay através da criação artística. A explosão da arte homossexual é uma demanda dos gays que estão cansados de consumir arte que não os mostra como realmente são e que não debate suas verdadeiras questões. A arte gay cresce por que o dinheiro gay cresce e quer o entretenimento que promova reconhecimento e reflexão.

Como última fonte de referência para a realização deste projeto está $A$ coluna do meio, do produtor cultural Celso Curi, no jornal Última Hora. Por se tratar da primeira coluna sobre comportamento e cultura gay na América Latina, oferece os mais preciosos registros sobre a vida cultural GLS em São Paulo.

Surgem algumas pistas na produção teórica norte-americana para tentarmos um entendimento do que seria uma gay play. Uma alternativa estaria na bibliografia atual sobre a Queer Theory como um braço dos Gay and Lesbian Studies. Mas será que a produção gay veste bem a definição ainda em processo e não menos volátil de queer? Como bem observa Judith Butler: "normalizar o queer seria, no final das contas, o seu triste fim".

Alguns teóricos e artistas mais ortodoxos chegam mesmo a entender que a gay play deve ser endereçada a um público gay, apresentando-se em locais/guetos deste público gay, por artistas assumidamente homossexuais, etc. Esta conceituação pode ser entendida porque a realidade ativista norte-americana está consolidada. O teatro foi desde cedo campo de batalha para a luta pelos direitos da comunidade homossexual norte-americana. Há um histórico forte de grande produção de espetáculos gays nos Estados Unidos no formato da stand-up comedy ou de caráter performático; e muitas apresentadas para grupos específicos: Lésbicas chicanas, comunidade afro-gay-norte-americana, etc. (Obviamente, há um bom tempo algumas produções já alcançaram a Broadway e offBroadway, sendo alçadas ao reconhecimento do grande público). 
Mas nossa prática ativista está dissociada deste compromisso com o teatro. Com poucas exceções, a partir da década de 1990 (em torno disto), os chamados Gay Nineties, uma produção mais constante vem se firmando nos palcos paulistas especificamente (de textos de autores nacionais e de estrangeiros). Esta produção da década de 1990 constitui nosso objeto específico de análise.

Há uma constante dificuldade em aceitar esta delimitação de objeto de estudo. Porque peças sobre homossexuais, se não existem peças sobre heterossexuais? Não seria reducionista? ou até mesmo preconceituoso, retornar à idéia de gueto? De teatro de minorias? E se há a gay play, qual a sua especificidade, quais os seus limites, o que torna um texto apto a esta qualificação? Seria esta uma discussão que se esgota na temática ou que abraça aspectos formais, estéticos, artísticos? E mais: não deveríamos talvez entender o nosso modo de produção e as raízes de nosso histórico cênico homoerótico, em vez de adotarmos conceitos produzidos por outra vivência estética?

De qualquer modo, buscamos aqui um corpo teórico que nos alicerce a seguir o seguinte propósito: vasculhar o universo gay presente na História dos palcos brasileiros, mas sem pretender apresentar nenhuma solução conceitual. Neste primeiro momento, valemo-nos do critério temático para realizar este panorama para talvez, futuramente, elaborar outros possíveis critérios de entendimento do conceito de peça gay.

Ao mergulhar nas escavações destas peças, a maior dificuldade encontrada é de longe o parco registro oficial de algumas produções, na imprensa ou mesmo em Bibliotecas Públicas. Artistas como Hilton Have, Fernando Neves, Gustavo Mendes, famosos por suas produções underground - ou seria melhor dizer udi-grudi - na noite paulistana, são raramente mencionados na mídia da época. Até hoje há que se tentar montar o quebra-cabeça ou o caminho das pedras que nos levará aos textos de Darcy Penteado. A engrenagem do meio e Crescilda e os espartanos, de sua autoria, são tidos como dois textos inovadores sobre a temática, mas onde encontrá-los?

Torna-se importante também desenvolver um interesse arqueológico, visto que inúmeros textos encontram-se guardados, esperando que os façamos 'sair da gaveta'. Tem-se a sensação que a dramaturgia gay nunca rareou, apenas não tinha espaço para ser produzida e, frente ao receio do fracasso ou a falta de produtores, muitos escritores enterraram seus textos. Isto sem mencionar o temor de alguns artistas de se verem vinculados ao universo gay. Hoje em dia, o jogo parece se inverter: interpretar um papel gay dá prestígio, passa uma imagem politicamente correta, mesmo que o contexto em que se insere o homossexual não receba um tratamento tão interessante assim. Mas nem sempre foi assim.

No Brasil, Qorpo Santo em A Separação de dois esposos, e Coelho Neto em Os mistérios do sexo ou $O$ patinho torto são exemplos da primeira metade do século que retratam de modo irreverente personagens gays. Não se tratam de peças que discutam exatamente o homoerotismo. Em Qorpo Santo, encontramos dois personagens que aparecem na última parte da peça e revelam, abertamente, através de uma briga conjugal, que constituem um casal gay. $\mathrm{Na}$ verdade, a cena mostra o rompimento dos dois porque um deles, Tamanduá, deseja fazer sexo com seu parceiro, Tatu. Mas Tatu repudia seu pedido e terminam a peça separados:

"Pois já que não se contenta com o nosso casamento espiritual somente, sendo ambos homens! Já que quer o imundo e absurdo casamento carnal, declaro-lhe que não sou mais seu sócio. (Empurrando-o)”.

No texto de Coelho Neto, o costume de criar meninos vestidos de mulher rende boas gargalhadas, mas o que poderia ser uma discussão mais profunda sobre papéis sexuais e travestimento, esvai-se no desfecho menos arriscado de uma comédia despretensiosamente bem construída. Roberto Gomes e João do Rio são autores que devem ser citados por tangenciar em algumas de suas obras para o teatro alusóes 
ao tema, mas nunca tratando diretamente do assunto. Preferem sugerir e criar atmosferas na construção de seus personagens. João do Rio arrisca-se mais ao construir, por exemplo, sua personagem Eva, em peça de mesmo nome, com ambígua sensualidade. Em uma das passagens, Eva flerta com Adalgisa Prates, dirigindolhe galanteios e elogios à aparência: "Sabes que ficaste mais linda agora à noite?”

O mapeamento segue esbarrando em personagens gays presentes na obra de escritores consagrados como Nelson Rodrigues (Toda Nudez Será Castigada, Álbum de Família), Plínio Marcos (Navalha na Carne), ou mesmo nas inúmeras Revistas de Ano. Mas as peças que enfrentem as questões do homoerotismo só se firmam na segunda metade do século.

Antes de discorrermos sobre a produção dramatúrgica, ressaltamos, nos anos 1970, dois experimentos marcantes de transgressão: o Dzi Croquetes e o Vivencial Diversiones. Os Dzi Croquetes surgiram no começo da década de 1970 no Rio de Janeiro, implodindo com os conceitos de papéis sexuais. Apresentavam-se androginamente no palco, vestidos com símbolos masculinos e femininos; barbas e batom, soutien e cueca. Os Dzi não se diziam engajados à causa gay, 'apenas' defendiam a liberdade de expressão. Com uma força criativa contestatória, eles se apoiavam na tradição antropofágica e paródica da revista brasileira e, mesmo sem um discurso organizado e um texto teatral linear, tornaram-se um marco para liberação gay que se processou em seguida.

O Vivencial Diversiones, por outro lado, é um grupo bem menos conhecido. Fundado em Recife em 1979, seus componentes eram favelados, marginalizados, excluídos, intelectuais e travestis, que encenavam, num pequeno café de periferia, de gags picantes e números de dublagem a trechos de As criadas de Jean Genet. Tornou-se o maior sucesso off-off-Broadway dos palcos nordestinos, atraindo o público heterossexual em massa. Sua estética, ao contrário do Dzi, era trash, de poucos recursos, da reinvenção da pobreza e do lixo, ganhando uma poesia simples e cruel.
Greta Garbo quem diria acabou no Irajá, de Fernando Melo, foi um dos grandes sucessos da década de 1970, tendo sido remontada diversas vezes em várias cidades do país. Contava a história de uma bicha velha que acolhe um rapaz recém-chegado do interior sem estofo para entender a máquina de moer da cidade grande, o Rio de Janeiro. Este homossexual apaixona-se pelo rapaz e sofre posteriormente com o triângulo amoroso formado pelos dois e uma prostituta. Muito se fala da construção caricatural da bicha nesta peça e mesmo das limitaçôes formais de sua escritura, mas em Greta Garbo tivemos um protagonista gay assumido que foi sucesso de público em várias capitais do país.

Contudo, um grande desserviço a qualquer idéia de construção de uma imagem positiva do gay em cima dos palcos deste país pode ser encontrado nos espetáculos $O$ entendido e $O$ unissex, que tinha o sugestivo subtítulo de Uma comédia para rir de costa, ambos protagonizados por Costinha. Escreveu Macksen Luiz, no Jornal do Brasil de 02/06/79, de forma conclusiva sobre o espetáculo: "na aparente crítica, Costinha reforça todos os preconceitos, revelando-se um moralista de atitudes e comportamento medievais".

$\mathrm{Na}$ outra ponta do iceberg, segue-se uma fase de tradução de grandes sucessos nos palcos mundiais, como Garotos da Banda (Boys in the Band), de Mart Crowley, e Bent, de Martin Sherman. E artistas como Carlos de Simoni, Ronaldo Ciambroni, Hilton Have, Hugo de La Santa, Zeno Wilde, Miguel Magno, Elias Andreato, Raul Cortez, Maurício Abud e Rubens Côrrea desenvolveram espetáculos que discutiam questôes do universo gay e/ou se valiam da arte do travestimento em suas criações. Por exemplo: Terezinha de Jesus, Nossa Sra. das Flores, Donana, Quem tem medo de Itália Fausta, Hello Boy, Giovanni, O beijo da mulher-aranha.

Há de se mencionar Caio Fernando Abreu. $O$ homem e a mancha, texto escrito para o teatro, dirigido por Luiz Arthur Nunes, e $A$ dama da noite, adaptação de um conto, dirigido por 
Gilberto Gawronski e Hélio Dias, são exemplos de montagens bem-sucedidas da considerável produção do escritor. Experimentos outros a partir da obra de Caio despontam no histórico da dramaturgia paulista, como: Morangos mofados, com direção de Paulo Yutaka em 1984, e $\grave{A}$ beira do mar aberto, dirigido por Gilberto Gawronski em 1985. Caio merece maior atenção por se mostrar um dos autores sobre o tema mais montados em palcos brasileiros e com visível aceitação de público e crítica.

$O$ homem e a mancha trata de um tema que vem detonar a dramaturgia gay, a Aids. Aids que surgiu como uma provação para a comunidade gay, solicitando organização e posicionamento. De uma hora para outra, os gays viraram mensageiros da praga, arautos do apocalipse, disseminadores da morte. Muitas fissuras aconteceram internamente no mundo gay. Muitos tiveram que sair do armário, a afirmação que vinha crescendo, solidificou-se. Para exigir um posicionamento, era vital esclarecer a população e se fortalecer para curar seus doentes. No teatro, surgiram as primeiras Aids Drama, peças sobre homossexuais na era pós-Aids, como The Normal Heart, de Larry Kramer, mas o texto precursor a tratar do tema no Brasil foi Por que eu?, dirigido por Roberto Vignatti e estrelado por Carlos Augusto Strazzer, ainda na década de 1980.

Sucessos nos Estados Unidos, foram encenadas aqui Angels in America e Algo em comum (On Tidy Endings). A primeira, com texto de Tony Kushner, tem como fio condutor da peça um casal norte-americano gay, Louis e Prior, que descobre a Aids. Prior confirma o diagnóstico da doença e comunica a Louis, que não consegue conviver com a idéia da perda do companheiro e do contágio. Louis abandona-o no momento em que Prior mais precisava e carrega a culpa por isto. Dentre outras questóes, como a política da era Reagan no combate a Aids, Kushner retrata a crise pela qual passaram vários casais gays, encurralados com a doença, a exposição que ela empunha e o abandono.

Algo em comum, de Harvey Fierstein, levantava outras questões ao pôr em discussão uma herança afetiva entre viúva (ex-mulher) e viúvo (ex-namorado) de um mesmo homem. Em meio a lembranças e comparaçōes de recordaçôes da vida a dois, descobre-se que a grande herança deixada pelo morto à ex-mulher era o vírus da Aids, adquirido em suas escapadas bissexuais durante o tempo em que foram casados, enquanto o namorado fora protegido e poupado do contágio pelo marido. A bissexualidade e suas armadilhas, a Aids como trator que deixou cair o véu da bissexualidade dissimulada e negociada em casamentos aparentemente sólidos. Vale lembrar que outro texto de Harvey Fierstein, Safe Sex, ainda inédito no Brasil discute as relações dentro da comunidade gay após o advento do sexo seguro, instituído pela comunidade gay para sobreviver.

Ironicamente, através da dramaturgia sobre a Aids cresce a visibilidade em torno do mundo gay e sua produção cultural é alavancada. Os chamados Gay Nineties acolhem uma crescente oferta de títulos sobre o universo gay: Pobre Super-Homem, de Brad Fraser; Espelhos e sombras, de Avelino Alves; Sereias da Rive Gauche, de Vange Leonel; Esta noite ouvirei Chopin, de Sérgio Pires; Oscar Wilde, de Oscar Wilde (org. Elias Andreatto); Tango, bolero e chá-cháchá, de Eloy Araújo; Violeta Vita, de Luiz Cabral; Nocaute, de Cláudia Schapira; Pólvora e poesia, de Alcides Nogueira; Vidas calientes, de Luque Daltrozo; Risco de vida, de Alberto Guzik; Deus sabia de tudo e não fez nada, de Newton Moreno; Dilemma, de Kris Niklisson; Estranho Amor, de Olair Coan; entre outros.

Paralelamente, outra produção, geralmente rechaçada pela inteligentsia gay engajada continua a demarcar seu terreno. Geralmente encenada na região mais central da vida noturna paulistana, nos bairros da República, Centro, Bela Vista, espetáculos como: Romeu e Romeu, Garoto de programa, Garotos da sauna e outro títulos sugestivos constituem uma oferta mais esteticamente empobrecida.

Ao chegar na década de 1990, sublinhamos um evento de fundamental importância para a explosão destas encenações: o Ciclo de 
Leituras Dramáticas OffMix 99, promovido pelo espaço cultural N.Ex.T e organizado por Celso Curi, em São Paulo. Braço cênico do Festival de Vídeo e Filmes MixBrasil de Diversidade Sexual, o OffMix reuniu um série de textos teatrais inéditos que nos anos seguintes foram montados, como as já citadas Pobre Super-Homem (Prêmio APCA 2000 de Melhor Direção), Risco de vida, Deus sabia de tudo e não fez nada, Pólvora e poesia (Prêmios Shell 2002 de Melhor Texto, Ator e Autor) e As sereias da Rive Gauche. A peça Vidas calientes, do curitibano Luque Daltrozo, que esteve em cartaz em 2001, também foi anteriormente lida num embriāo do OffMix, no evento de 1998 do MixBrasil.

Vange Leonel, com As sereias da Rive Gauche, apareceu na mostra como única representante feminina. Tratava-se de uma peça com forte pesquisa sobre sete mulheres lésbicas na França dos anos 1920, e continha citações de textos de Radclyffe Hall, Djuna Barkes e Natalie Barney. Mesmo em menor número, as meninas estiveram representadas nos palcos paulistas em belas montagens como: Violeta Vita, de Luiz Cabral, Um Porto para Elizabeth Bishop, de Marta Góes (indicado ao Prêmio Shell 2002 de Melhor Texto), e Sappho de Lesbos, de Ivan Cabral e Patricia Aguille.

Em temporada relâmpago no Festival de Curitiba de 2001e no SESC Ipiranga em São Paulo, assistimos a Dilemma, de Kris Niklison. O espetáculo, construído com técnicas circenses de trapézio, representava um grande metáfora do risco e delícia de se experimentar um grande amor. Na peça, entre duas mulheres.

Fora do eixo Rio-São Paulo, no Nordeste brasileiro proliferam criações cênicas calcadas na arte do travestimento, geralmente formadas por cômicos ágeis, mestres na arte do improviso e nos números de platéia. Algumas dessas montagens apresentam versões paródicas de 'clássicos' da dramaturgia e literatura mundiais. Grupos como A Trupe do Barulho, em Recife, a Companhia Baiana de Patifaria, em Salvador, e artistas como Ciro Santos e Antônio Fernandes, em Fortaleza, alimentam-se desta tradição.
É o caso da bem-sucedida versão para os palcos de Cinderela em Cinderela, uma estória que sua mãe não contou, da Trupe do Barulho. Montada em Recife no ano de 1991, a peça permaneceu em cartaz por 10 anos, cumprindo temporadas em vários estados nordestinos, Rio de Janeiro e São Paulo. Tornou-se incontestável sucesso de público, reunindo longas filas às sextas e sábados, à meia-noite, no Teatro Valdemar de Oliveira (paradoxalmente, berço do mais tradicional e antigo grupo teatral de cidade, o TAP, Teatro de Amadores de Pernambuco).

Como o próprio grupo definia no programa: "Cinderela é uma empregadinha que sonha encontrar seu príncipe num show de dublagens".

Não há atrizes em cena. Cinderela, Madrasta, Irmãs, Fadas, todas as personagens femininas são defendidas por atores e até mesmo o príncipe nos é apresentado com longos cachos dourados, frágil compleição e trejeitos bem efeminados. Uma grande fantasia gay, onde a única intervenção mais máscula surge em off, na voz do Rei, que exige que o príncipe escolha uma companheira.

O grupo define a peça como um dos clássicos do besteirol pernambucano. Sem avançar em questôes sobre os limites desta dramaturgia, ou de críticas à paródia, o que impressiona em Cinderela é a construção das personagens, o poder de comunicação e improviso de seus intérpretes; e a incrível legião de fãs do espetáculo que enfrenta filas, leva familiares, maridos, esposas, mães, sogras para assisti-lo. Um terreno em que a homossexualidade acontece livre de imprecações. A arte do travestimento parece aqui redimir aqueles artistas de suas verdadeiras opções sexuais. Essa platéia ávida pelo entretenimento proposto por um grupo de homens vestidos e caracterizados como mulher nos faz retornar à origem do teatro, onde papéis femininos eram interpretados por homens.

No próprio Carnaval de rua essa tradição se mantém mais forte e presente. Inúmeros blocos são compostos integralmente por homens vestidos de mulher, geralmente satirizando 
acontecimentos marcantes. Como era feito nas Revistas de Ano. Os mais famosos deles são As Virgens de Olinda, que tomam as rua da cidade histórica para anunciar o início da festa momesca, e seu dissidente As Virgens de Verdade.

A Cia. Baiana de Patifaria representa um outro parâmetro de análise. Fundada na década de 1980, tem o melhor histórico comercial, constituindo-se num verdadeiro sucesso de marketing para um grupo de artistas que se travestem em cena, assumindo papéis femininos e masculinos. Seus textos não trazem nenhuma discussão objetiva sobre a homossexualidade, constróem o espetáculo na excelência da arte do travestimento, na capacidade de improviso de seus integrantes e na roupagem dinâmica para clássicos do besteirol. Marcam contemporaneamente a mais rentável experiência do travestimento cênico e a aceitação definitiva por parte do grande público. Assim como uma série de comediantes cearenses que lotam as casas de espetáculo da cidade com espetáculos como Titia te ama, meu amor, de Ciro Santos, Três donzelas e uma comédia, de Paulo Diógenes, ou mesmo na versão irreverente de Dona Flor e seus dois maridos, de Jorge Amado, tendo a personagem Skolástica, criação do ator Antônio Fernandes, no papel consagrado por Sônia Braga.

Em espaços não convencionais, o teatro gay teve duas montagens de pouca repercussão que não lograram êxito em suas bem-intencionadas tentativas de levar um texto teatral dentro da boate So-Go, nos Jardins em São Paulo. Espelhos e sombras, com texto de Avelino Alves e dirigido por Alexandre Roit, contava a história de um homem atormentado pelos fantasmas de sua mal-resolvida sexualidade. O outro experimento foi a montagem brasileira de The Night Larry Kramer Kissed Me, de David Drake, aqui intitulada Atitude, dirigida por Marco Antônio Pâmio e estrelada por Roberto Rocha. Ambas sem grande retorno de público e crítica, não tiveram longa vida, indício que o público que alimenta a noite gay paulistana não se interessa por uma produção cultural mais reflexiva. Vale lembrar que nestas mesmas boates, outros artistas, drag-queens e transformistas agradam com seus números de platéia e dublagens.

Nanny People, drag-queen famosa no mundo gay paulista, pôde ser vista no espetáculo Um homem é um homem, de Bertolt Brecht, com direção de Marcelo Fonseca. Antes dela, os travestis Rogéria e Claúdia Wonder arrancaram elogios por suas interpretações em, respectivamente, Gay Fantasy e Nossa Senhora das Flores. Rogéria recebeu inclusive uma indicação ao prêmio Molière de Teatro como Melhor Atriz. Nanny, Rogéria e Cláudia realizaram com sucesso o trânsito entre o terreno alternativo para experimentos dentro de montagens profissionais de teatro, reconhecidas pela classe e pelos críticos.

Assim como no caso da trajetória destas artistas, é possível vislumbrar desdobramentos para todo este generoso universo da cena gay no Brasil. Na pesquisa, arrisco-me a ser seduzido pelo estudo mais acurado da arte do travestimento dos primeiros atores dos palcos brasileiros. Quem foram 'essas grandes atores' que atravessaram a época de Martins Pena, de Miguel Magno e desembocaram nas divertidas encenações da Cia. Baiana de Patifaria? Sem mencionar o travestimento como artifício dramatúrgico, geralmente cômico, presente em $A s$ desgraças de uma criança, de Martins Pena, por exemplo.

Não me furto também a desenvolver um profundo interesse por uma outra construção dramatúrgica presente na cena gay noturna: o performer da boate que cria o seu texto, os seus lazzi, suas gags, dublagens, roteiros, piadas, número de platéia, enfim toda uma rede de significados que se constrói neste universo, o qual denomino de 'o texto da noite'. Evidencio ainda, num último parágrafo, a necessidade de se olhar para o fenômeno da 'drag-queen' como um estudo de máscaras contemporâneas.

E, por fim, rendo meu último capítulo a uma aproximação possível do Vivencial Diversiones, visto que trabalho com um grupo extinto e cujos últimos membros residem todos em Reci$\mathrm{fe}$, no Nordeste brasileiro. Esta experiência é da maior transgressão, da mais radical provocação 
ao juntar os excluídos para que eles respondam à sociedade, criando beleza. Mais: produzindo uma arte que não nega quem eles são, que não fantasia quem eles são. Um arte à margem que se utiliza dos restos, do 'pouco', do lixo para criar. E que dá, por exemplo, ao travesti e ao transexual a possibilidade de ser um artista. Não apenas manicure, cabeleireiro ou prostituto, oferece uma outra imagem possível para uma das mais desgastadas figuras do universo gay, a traveca.

Temos que concluir sinalizando os novos autores teatrais que reafirmam seu interesse em pesquisar esta inquieta dramaturgia gay. Sérgio Pires, formado pela Escola Livre de Santo André, no ABC paulista, fortalece seu olhar para o mundo gay em textos como Esta noite ouvirei Chopin. Antônio Rogério Toscano estréia este ano Leo não pode mudar o mundo, de indisfarçada inspiração na obra de Leonilson, para falar do amor gay entre adolescentes. De sua autoria ainda permanecem inéditas $O$ leopardo e Vênus em fúria. Luque Daltrozo promete ainda para 2002 a montagem de $O$ beijo do escorpiāo, liderando uma lista de outros autores curitibanos que escreveram sobre o tema, como César de
Almeida, que apresentou seu texto Ardor na Mostra Fringe da última edição do Festival de Curitiba de 2002. Cláudia Schapira, que volta a despontar como a mais eminente dramaturga sobre o universo gay, escreveu, em 2002, Bruta Flor, ainda inédito.

Nesta lista, incluo Newton Moreno, que após seu primeiro texto Deus sabia de tudo e não fez nada, apresenta este ano os textos Dentro, na Mostra de Dramaturgia Contemporânea do SESI, e Agreste, ainda sem data de estréia.

Ao que parece, finalmente a dramaturgia gay 'saiu da gaveta' e veio para assumir seu lugar, com um farto leque de abordagens. Mas uma questão crucial é a compreensão de que a construção da discutida 'identidade gay' parece-me infrutífera. Deve-se falar em identidades, sexualidades. Não se pode aprisionar a diversidade. Ainda mais nesse momento em que a comunidade gay experimenta a visibilidade e se expõe em toda sua complexidade de relacionamentos, práticas e famílias. E, ao se expor, a identidade gay se modifica. Sexualidade em ebulição. Constrói-se e reconstrói-se. Dia a dia, público a público.

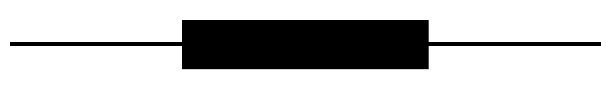

\section{Referências bibliográficas}

DOLAN, Jill. Presence and Desire: essays on gender, sexualty, performances. Michigan: University of Michigan Press, 1993.

JONGH, Nicholas de. Not in Front of the Audience: homosexuality on stage. Londres: Rouledge, 1992.

TREVISAN, João Silvério. Devassos no paraíso: a homossexualidade no Brasil, da Colônia à atualidade. São Paulo: Max Limonad, 1986. 